DEPARTMENT OF THE INTERIOR

U.S. GEOLOGICAL SURVEY

\title{
Debye temperatures of selected silicate minerals \\ by
}

Richard A. Robie

U.S. Geological Survey

Reston, VA $22092^{1}$

Open-File Report $88-663$

This report is preliminary and has not been reviewed for conformity with U.S. Geological Survey editorial standards.

${ }^{1}$ USGS duty station 
The acoustic Debye temperatures, $\theta_{D}^{e}$, for 31 silicate minerals have been calculated from their elastic stiffness $\left(c_{i j}\right.$ 's) constants and/or their heat capacities at very low temperatures. Calculation of the $\theta_{D}^{e}$ values from the $c_{i j} s^{\prime}$ were done on a Hewlett-Parkard series 200 computer using a program written in Hewlett-Packard BASIC.

For those silicates having no magnetic or electronic contributions to their heat capacity for which modern heat capacity measurements below $20 \mathrm{~K}$ exist, the calorimetric Debye temperatures, $\Theta_{D}^{c}$, are in good agreement with $\theta_{D}^{e}$ values obtained from the elastic constants.

\section{INTRODUCTION}

Debye's (1912) theory for the heat capacity of a solid provides a simple one parameter model which correctly describes the temperature dependence of $\mathrm{C}_{\mathrm{V}}$ at low temperatures. It is based upon a model for the frequency spectrum, $G(v)$, of a solid whose significant features are a cutoff or maximum frequency $\nu_{\max }$, a total of $3 \mathrm{~N}_{A}$ frequencies where $\mathrm{N}_{\mathrm{A}}$ is Avogadros constant, and a quadratic variation of the number of frequencies (i.e., $d n / d v \sim v^{2}$ ) at low frequency. Debye's model spectrum is given by (e.g. Zemansky, 1968)

$$
G(v)=\left(9 N_{A} / v_{\max }^{3}\right) v^{2}
$$

The Debye temperature, $\theta_{\mathrm{D}}^{e}$, is directly related to this maximum frequency by

$$
\theta_{D}^{e}=(h / k) v_{\max }
$$

or, to the mean velocity of sound in the crystal by

$$
\theta_{D}^{e}=(h / k)[3 N \rho / 4 \pi M]^{1 / 3} v_{m}
$$

where $\mathrm{h}$ is Planck's constant $=6.626076 \times 10^{-34} \mathrm{~J} \cdot \mathrm{s}, \mathrm{k}$ is the Boltzman constant $=1.38066 \times 10^{-23} \mathrm{~J} \cdot \mathrm{K}^{-1}$, Avogadros constant, $\mathrm{N}_{\mathrm{A}}=6.0221367 \times 10^{23} \mathrm{~mol}^{-1}, \rho$ is the density, $M$ the formula weight, and $v_{m}$ is the mean velocity of sound. 
Because of the simplicity of the theory and its considerable success in calculating the heat capacity at low temperatures, the concept of a characteristic or Debye temperature has become a central concept in the equation of state of solids. Thus the Debye temperature enters into the Grüneisen theory of thermal expansion, the Lindemann melting relation, and as pointed out by Anderson (1965), given the Debye temperature one may estimate fairly closely the velocity of shear waves in a solid from the approximate relation

$$
\mathrm{v}_{S} \approx\left(\theta_{D} / 280\right)(M / q \rho)^{1 / 3} \mathrm{~km} \mathrm{sec}^{-1}
$$

where $\mathrm{q}$ is the number of atoms in the chemical formula. Thus values for the Debye temperature are of some use to the geophysicist trying to model the thermal parameters of mantle minerals.

\section{$\theta_{\mathrm{D}}$ FROM $\mathrm{C}_{\mathrm{p}}^{\circ}(\mathrm{T})$ MEASUREMENTS}

At sufficiently low temperatures the vibrational spectrum of a solid is composed of frequencies in the "acoustic" range (i.e., $5 \times 10^{13} \mathrm{sec}^{-1}$ or less), optical frequencies are not excited and the heat capacity is given by (e.g., Slater, 1939)

$$
C=\frac{12 R \pi^{4}}{5}\left(\frac{T}{\theta_{D}}\right)^{3}=1943.8\left(\frac{T}{\theta_{D}}\right)^{3}
$$

where $\mathrm{R}=\mathrm{N}_{\mathrm{A}} \cdot \mathrm{k}$ is the gas constant, $=8.31451(7) \mathrm{J} \cdot \mathrm{mol}^{-1} \cdot \mathrm{K}^{-1}, \mathrm{~T}$ is the Kelvin temperature, and $\mathrm{C}=\mathrm{C}_{\mathrm{v}} \approx \mathrm{C}_{\mathrm{p}}^{\circ}$. Thus $\mathrm{C}$ will vary as $\mathrm{T}^{3}$ and a plot of $\mathrm{C} / \mathrm{T}$ against $\mathrm{T}^{2}$ will be a straight line passing through the origin. One may therefore obtain a purely acoustical value for the Debye temperature $\left(\theta_{D}^{c}\right)$ from heat capacity measurements at low temperatures using (5). We stress that equation (5) is valid only for temperatures of the order of $T<\theta_{D} / 50$. This is shown in Figure 1 where we have plotted the $C_{p}^{\circ}$ measurements of Krupka et al. (1985) for synthetic enstatite and wollastonite, and those of Hemingway et al. (1986) for phenakite. 
Equation (3) and (5) are applicable to monoatomic solids only. For a polyatomic solid one must multiply (3) by $\mathrm{q}^{1 / 3}$ and (5) by $\mathrm{q}$.

\section{${ }^{\theta_{D}}$ FROM ELASTIC CONSTANTS}

One may also obtain a (purely acoustical) value for $\theta_{D}$ from the mean velocity of sound in a crystal from equation (3). The difficulty in calculating a mean sound velocity in a low-symmetry crystal arises from the complex variation of $\mathrm{v}$ with direction as shown in Figure 2. For any direction in a crystal the velocity of sound can be calculated from the elastic stiffness constants and the density of the crystal by using the Christoffel equation

$$
\begin{array}{cccc}
\Gamma_{11}-\rho v^{2} & \Gamma_{12} & \Gamma_{13} \\
\Gamma_{12} & \Gamma_{22}-\rho v^{2} & \Gamma_{23} \\
\Gamma_{13} & \Gamma_{23} & \Gamma_{33}-\rho v^{2}
\end{array} \mid=0
$$

which is a cubic in $\rho v^{2}$. The $\Gamma_{i j}$ are complex functions of the elastic constants and of the direction cosines of the propogation direction of the sound wave. For any direction in the crystal there will be three solutions to this equation corresponding to the two shear (transverse) velocities and one longitudinal (compressional) velocity. By solving the Christoffel equation for various directions one may, by a numerical integration procedure, obtain the mean sound velocity. The calculational procedures are discussed in detail by Robie and Edwards (1966). Thus if we have values for the $c_{i j}$ for a crystal, we can obtain a purely acoustical value for the Debye temperature. To this end, the procedure described by Robie and Edwards (1966) was programmed in Hewlett-Packard BASIC for a personal computer. A listing of this program is given in the Appendix.

The development of the Brillouin scattering technique for measuring the velocity of sound in microcrystals by Weidner et al. (1975) together with 
the velocity inversion procedure to obtain the elastic stiffness constants by Weidner and Carleton (1977) was a major experimental advance and in recent years has provided accurate elastic constant data for a number of low-symmetry silicate minerals.

Because of the usefulness of the Debye model for extrapolating measured $\mathrm{C}_{\mathrm{p}}^{\circ}$ data to zero kelvin, we have collected the more recent elastic constant data for silicate minerals and used these data to calculate Debye temperatures. To be strictly rigorous one should compare the $\theta_{D}$ values obtained from low-temperature heat capacity data with $\theta_{D}$ calculated from elastic constants also measured at low temperatures. The temperature variation of the elastic constants is usually fairly small and can normally be neglected. As an example the Debye temperatures of forsterite calculated from the elastic constants of Sumino et al. (1977) measured at 83 and $293 \mathrm{~K}$ are 767 and $757 \mathrm{~K}$ respectively.

The results of these calculations together with the source of the elastic constants are listed in Table 1. Where available, we have also tabulated values for $\theta_{\mathrm{D}}^{c}$ calculated from low temperature heat capacity data in the temperature range $T<\theta / 25$. 


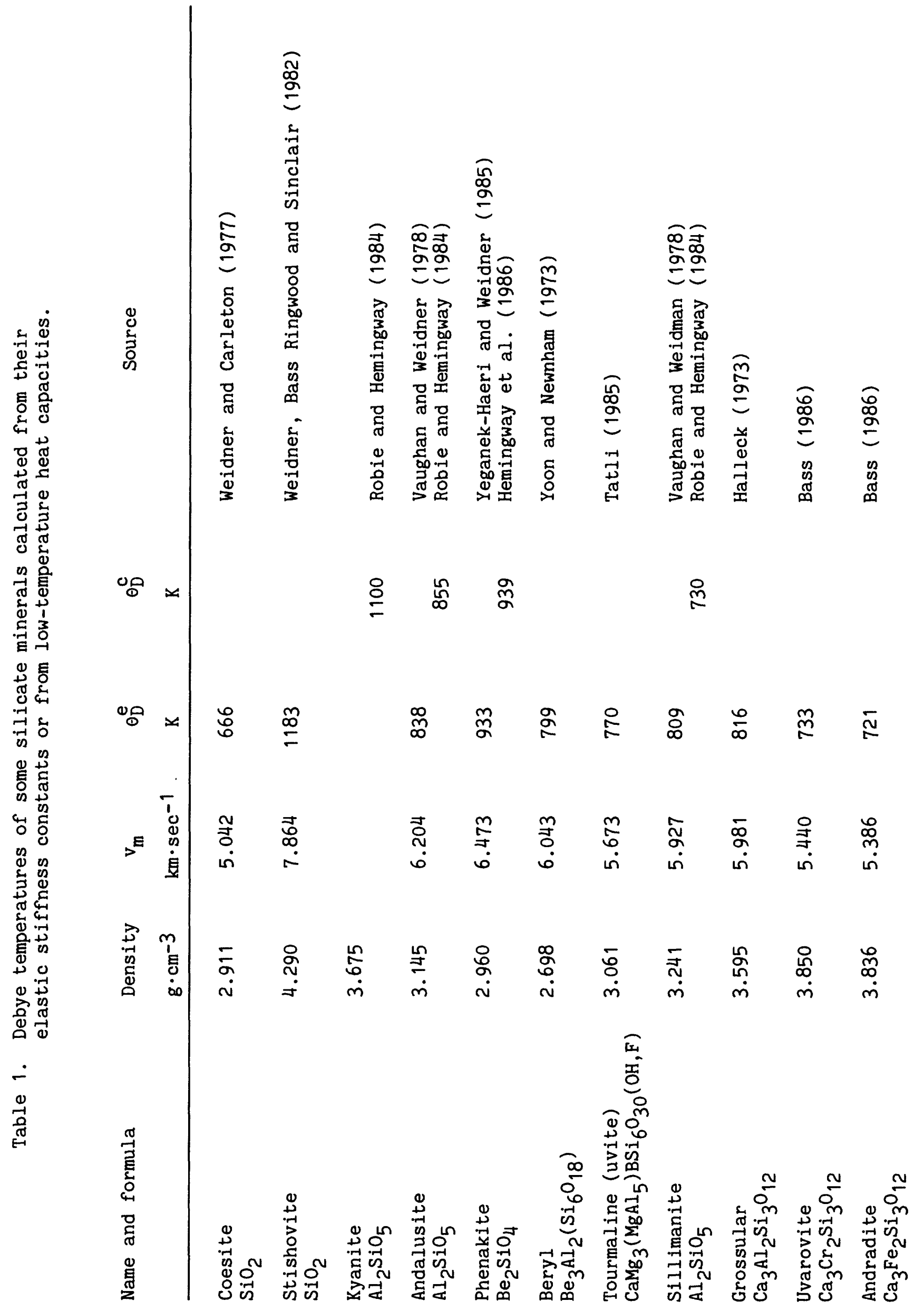




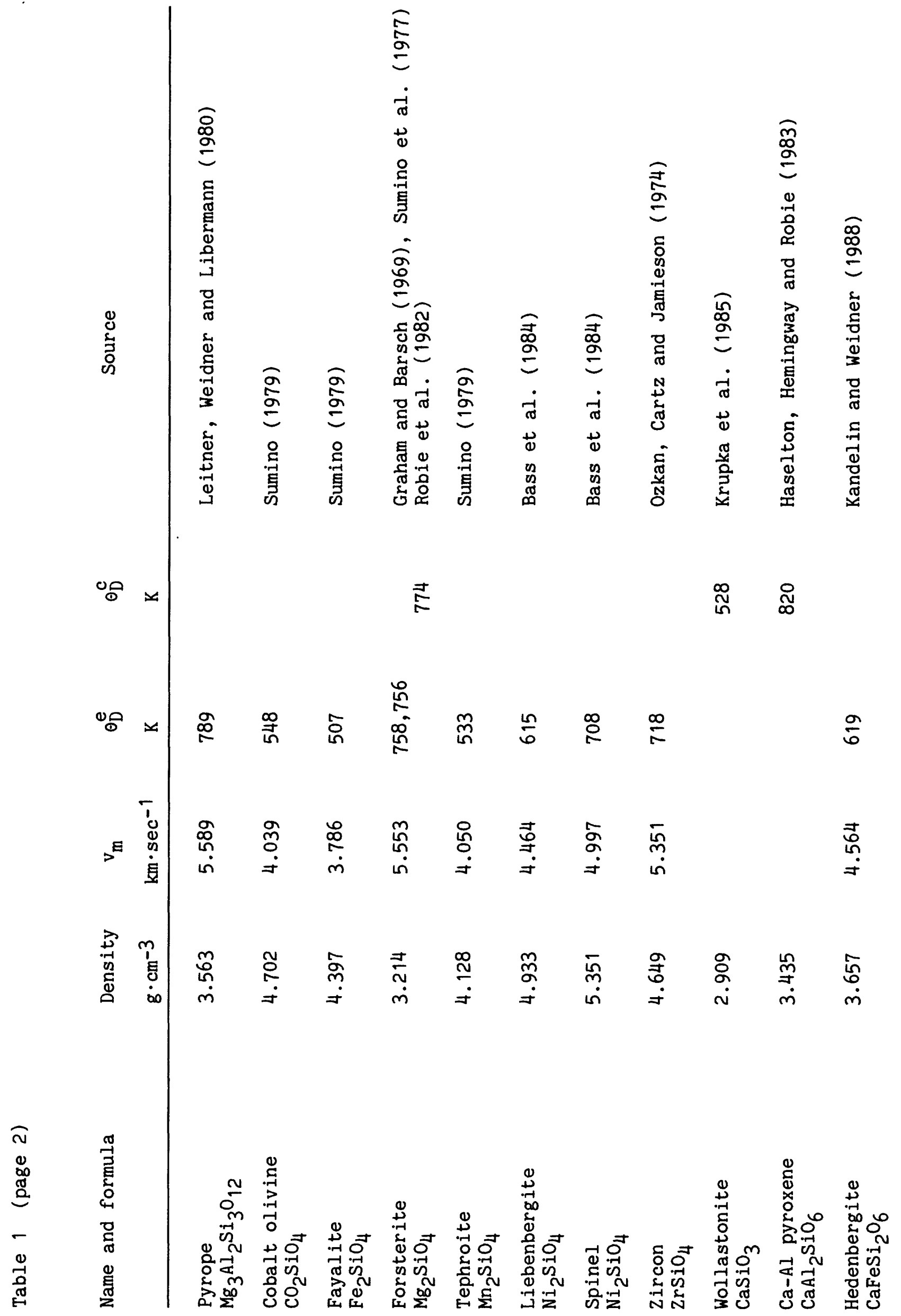




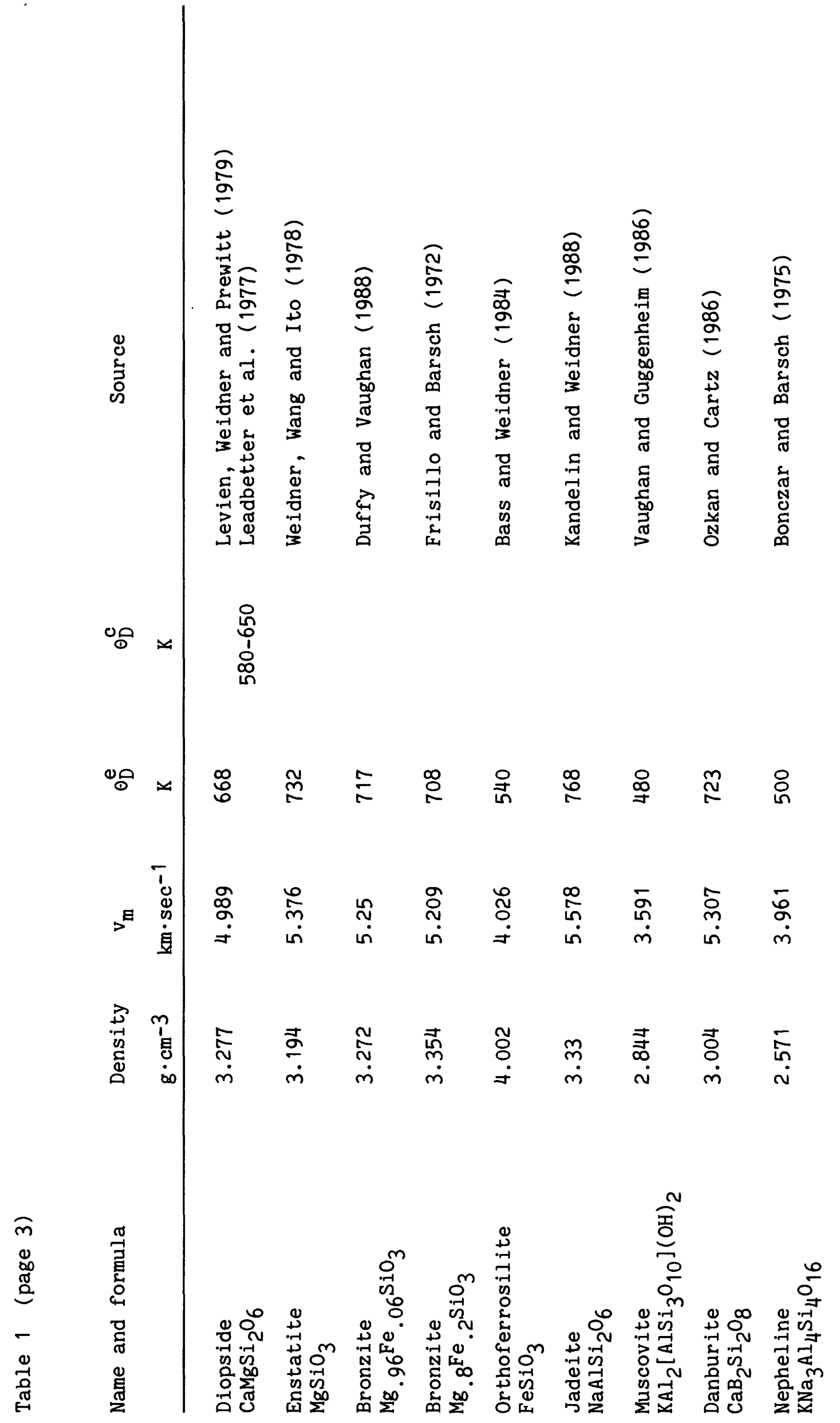




\section{REFERENCES}

Anderson, O.L., 1965, An approximate method of estimating shear velocity from specific heat. Journal of Geophysical Research, v. 70, p. 4726-4728.

Bass, J.D., 1986, Elasticity of uvarovite and andradite garnets. Journal of Geophysical Research, v. 91, p. 7505-7516.

Bass, J.D. and Weidner, D.J., 1984, Elasticity of single-crystal orthoferrosilite. Journal of Geophysical Research, v. 89, p. 4359-4371.

Bass, J.D., Weidner, D.J., Hamaya, N., Ozima, M. and Akimoto, S., 1984, Elasticity of the olivine and spinel polymorphs of $\mathrm{Ni}_{2} \mathrm{SiO}_{4}$. Physics and Chemistry of Minerals, v. 10, p. 261-272.

Bonczar, L.J. and Barsch, G.R., 1975, Elastic and thermoelastic constants of nepheline. Journal of Applied Physics, v. 46, p. 4339-4340.

Debye, P., 1912, Zur theorie der spezifischen Warmen. Annalen der Physik, v. 39, p. $789-839$.

Duffy, T.S. and Vaughan, M.T., 1988, Elasticity of enstatite and its relationship to crystal structure. Journal of Geophysical Research, v. 93, p. 383-391.

Frisillo, A.L. and Barsch, G.R., 1972, Measurement of single-crystal elastic constants of bronzite as a function of temperature and pressure. Journal of Geophysical Research, v. 77, p. 6360-6384.

Graham, E.K. and Barsch, G.R., 1969, Elastic constants of single-crystal forsterite as a function of temperature and pressure. Journal of Geophysical Research, v. 74, p. 5949-5960.

Halleck, P.M., 1973, The compression and compressibility of grossularite garnet: a comparison of $x$-ray and ultrasonic methods. Ph.D. Thesis, University of Chicago, Chicago, Illinois.

Haselton, H.T., Jr., Hemingway, B.S. and Robie, R.A., 1983, Low-temperature heat capacities of $\mathrm{CaAl}_{2} \mathrm{SiO}_{6}$ glass and pyroxene and thermal expansion of $\mathrm{CaAl}_{2} \mathrm{SiO}_{6}$ pyroxene. American Mineralogist, v. 69, p. 481-489. 
Hemingway, B.S., Barton, M.D., Robie, R.A. and Haselton, H.T., Jr., 1986, The heat capacity and thermodynamic functions for beryl, $\mathrm{Be}_{3} \mathrm{Al}_{2} \mathrm{Si}_{6} \mathrm{O}_{18}$, phenakite, $\mathrm{Be}_{2} \mathrm{SiO}_{4}$, euclase, $\mathrm{BeAlSi}_{4}(\mathrm{OH})$, bertrandite, $\mathrm{Be}_{4} \mathrm{Si}_{2} \mathrm{O}_{7}(\mathrm{OH})_{4}$, and chrysoberyl. American Mineralogist, v. 71, p. 557-568.

Kandelin, J. and Weidner, D.J., 1988, The single-crystal elastic properties of jadeite. Physics of the Earth and Planetary Interiors, v. 50, p. 251-260. Kandelin, J. and Weidner, D.J., 1988, Elastic properties of hedenbergite. Journal of Geophysical Research, v. 93, p. 1063-1072.

Krupka, K.M., Robie, R.A., Hemingway, B.S., Kerrick, D.M. and Ito, J., 1985, Low-temperature heat capacities and derived thermodynamic properties of anthophyllite, diopside, enstatite, and wollastonite. American Mineralogist, v. 70 , p. 249-260.

Leadbetter, A.J., Jeapes, A.P., Waterfield, C.G. and Wycherley, K.E., 1977, The low temperature heat capacity of some glass ceramics. Chemical Physics Letters, v. 52 , p. 469-471.

Leitner, B.J., Weidner, D.J. and Liebermann, R.C., 1980, Elasticity of single crystal pyrope and implications for garnet solid solution series. Physics of the Earth and Planetary Interiors, v. 22, p. 111-121.

Levien, L., Weidner, D.J. and Prewitt, C.T., 1979, Elasticity of diopside. Physics and Chemistry of Minerals, v. 4, p. 105-113.

Ozkan, H., Cartz, L., and Jamieson, J.C., 1974, Elastic constants of nonmetamict zirconium silicate. Journal of Applied Physics, v. 45, p. 556-562. Ozkan, H. and Cartz, L., 1986, Elastic constants of calcium borosilicate $\left(\mathrm{CaB}_{2} \mathrm{Si}_{2} \mathrm{O}_{8}\right)$. High Temperatures - High Pressures, v. 18, p. 675-678. Robie, R.A. and Edwards, J.L., 1966, Some Debye temperatures from single-crystal elastic constant data. Journal of Applied Physics, v. 37, p. 2659-2663. 
Robie, R.A., Hemingway, B.S. and Takei, H., 1982, Heat capacities and entropies of $\mathrm{Mg}_{2} \mathrm{SiO}_{4}, \mathrm{Mn}_{2} \mathrm{SiO}_{4}$, and $\mathrm{Co}_{2} \mathrm{SiO}_{4}$ between 5 and $380 \mathrm{~K}$. American Mineralogist, v. 67 , p. 470-482.

Robie, R.A. and Hemingway, B.S., 1984, Entropies of kyanite, andalusite, and sillimanite: additional constraints on the pressure and temperature of the $\mathrm{Al}_{2} \mathrm{SiO}_{5}$ triple point. American Mineralogist, v. 69, p. 298-306.

Slater, J.C., 1939, Introduction to Chemical Physics. New York, McGraw-Hill, $521 \mathrm{p}$.

Sumino, Y., 1979, The elastic constants of $\mathrm{Mn}_{2} \mathrm{SiO}_{4}, \mathrm{Fe}_{2} \mathrm{SiO}_{4}$ and $\mathrm{CO}_{2} \mathrm{SiO}_{4}$ and the elastic properties of olivine group minerals at high temperature. Journal of the Physics of the Earth, v. 27, p. 209-238.

Sumino, Y., Nishizawa, 0., Goto, T., Ohono, I. and Ozima, M., 1977, Temperature variation of elastic constants of single crystal forsterite between $-190^{\circ}$ and $400^{\circ} \mathrm{C}$. Journal of the Physics of the Earth, v. 25, p. 377-392.

Tatli, A., 1985, Zero-field elastic constants of uvite. Journal of Physies and Chemistry of Solids, v. 46, p. 1015-1018.

Vaughan, M.T. and Weidner, D.J., 1978, The relationship of elasticity and crystal structure in andalusite and sillimanite. Physics and Chemistry of Minerals, v. 3, p. 133-144.

Vaughan, M.T. and Guggenheim, S., 1986, Elasticity of muscovite and its relationship to crystal structure. Journal of Geophysical Research, v. 91 , p. $4657-4664$.

Weidner, D.J. and Carleton, H.R., 1977, Elasticity of coesite. Journal of Geophysical Research, v. 82, p. 1334-1346.

Weidner, D.J., Swyler, K. and Carleton, H.R., 1975, Elasticity of microcrystals. Geophysical Research Letters, v. 2, p. 189-192.

Weidner, D.J., Wang, H. and Ito, J., 1978, Elasticity of orthoenstatite. Physics of the Earth and Planetary Interiors, v. 17, p. 7-13. 
Weidner, D.J., Bass, J.D., Rigwood, A.E. and Sinclair, W., 1982, The singlecrystal elastic module of stishovite. Journal of Geophysical Research, v. 87, p. $4740-4746$.

Yeganek-Haeri, A. and Weidner, D.J., 1985, Single crystal elastic moduli of a beryllium silicate: phenacite $\left(\mathrm{Be}_{2} \mathrm{SiO}_{4}\right)$. EOS, v. 66, p. 358 .

Yoon, H.S. and Newnham, R.E., 1973, The elastic properties of beryl. Acta Crystallographica, v. A29, p. 507-509.

Zemansky, M.W., 1968, Heat and Thermodynamics (Fifth Edition). New York, McGraw-Hill, 657 p. 


\section{FIGURE CAPTIONS}

Figure 1. Low-temperature molar heat capacities for enstatite (squares) and wollastonite (triangles) from Krupka et al. (1985) and for phenakite (diamonds) from Hemingway et al. (1986) plotted as $\mathrm{C}_{\mathrm{p}}^{\circ} / \mathrm{T}$ against $\mathrm{T}^{2}$ for $T<\theta_{D} / 35$. Solid straight line correspond to calculated values using $\theta_{D}=939 \mathrm{~K}$ for phenakite, $692 \mathrm{~K}$ for enstatite, and $539 \mathrm{~K}$ for wollastonite.

Figure 2. Velocity of sound in muscovite in $\mathrm{km} / \mathrm{sec}$ in the (010) plane calculated from the elastic constants of Vaughan and Guggenheim $(1986)$ 


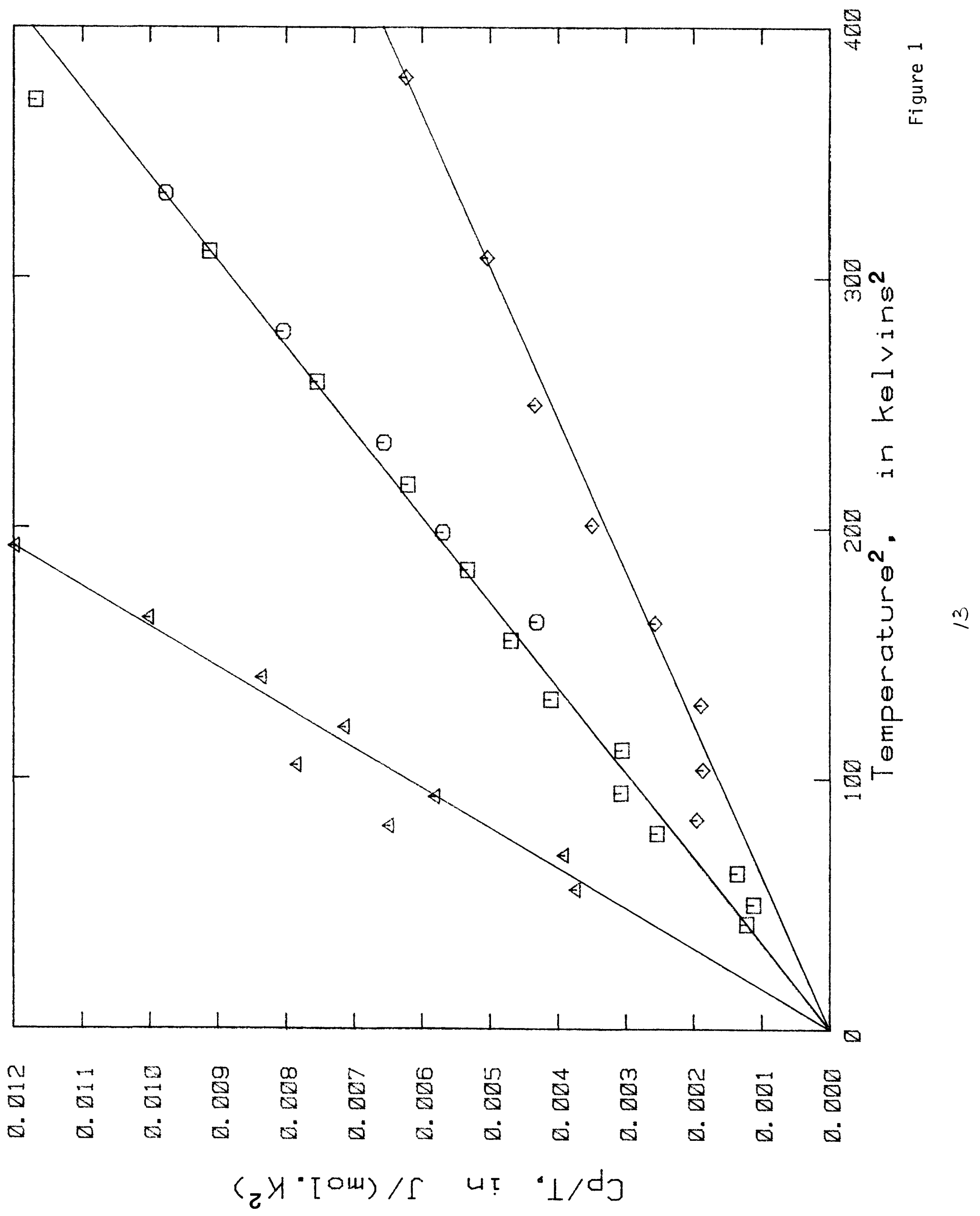




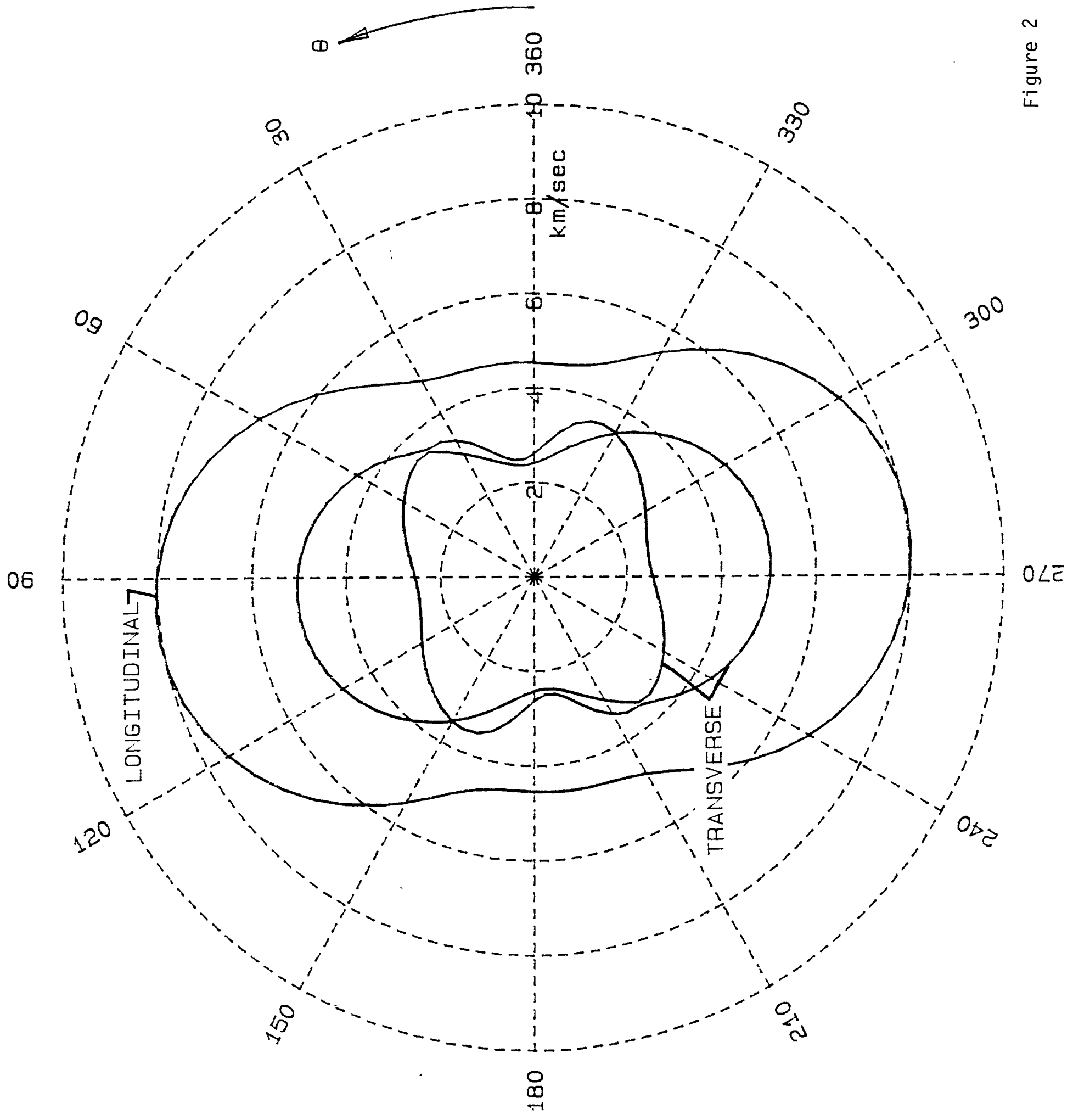




\section{APPENDIX}

A computer program was written in BASIC to calculate the mean velocity of sound given values for the single crystal elastic constants using the relations given by Robie and Edwards (1966). The program was written for a HewlettPackard 9826 computer. A listing of the computer program is given as Table 2 .

In response to the request by the computer, the user supplies the name, crystal density, crystal system, number of atoms in the formula, indicates whether the elastic constants are the stiffnesses $\left(c_{i j}\right)$ or compliances $\left(s_{i j}\right)$ and the initial, final and incremental values for the azimuthal angle $\Phi$, and similarly for the zenith angle $\theta$. The computer then solves for the 3 roots of equation (6) at each of the specified values of $\theta$ and $\Phi$ and numerically evaluates the following expression

$$
3 / v_{m}^{3}=\int_{0}^{4} \pi\left[\left(1 / v_{1}^{3}\right)+\left(1 / v_{2}^{3}\right)+\left(1 / v_{3}^{3}\right)\right](d \Omega / 4 \pi),
$$

where $v_{1}, v_{2}$, and $v_{3}$ are the roots of Eq. (5) and $d \Omega$ is the differential solid angle

$$
d \Omega=\sin \Theta d \theta d \Phi .
$$

to obtain the mean velocity of sound, and hence the Debye temperature.

The program lists the values for the sound velocity (two shear wave velocities and one longitudinal velocity) at each specified $\theta$ and $\Phi$. It can also generate a file of these velocities on a floppy fisk for use with a subsidiary plotting program. 
10 REM CRYSTAL WAVE VELOCITIES AND DEBYE TEMPS REVISED $12 / 2 / 1988$

$20 \mathrm{DIM} C(6,6), S(6,6), G(3,3), V(3), A 1(73,73), A 2(73,73), A 3(73,73), A 4(73,73), P 1 \$[$ 14], Name\$[60]

30 PRINT "NAME AND OTHER INFORMATION?"

40 INPUT Name\$

50 PRINT "DATE MM/DD/YY"

60 INPUT Day\$

70 PRINT "CRYSTAL SYSTEM CAN ONLY HAVE THE NAMES: CUBIC, TET, HEX, ORTH, MON, TRIG"

80 PRINT "CRYSTAL SYSTEM?"

90 INPUT System\$

$100 \quad P 1 \$=" 2(3 D), 3(2 D .3 D) "$

$110 \quad A \vee O g=6.022094 E+23$

$120 \quad H K=4.799281 E-11$

130 REM PRINT "IF THE ELASTIC CONSTANTS ARE $S(I, J)$ AND NOT C $(I, J)$ ENTER 1"

140 REM INPUT $J j j j$

150 PRINT "DENSITY?"

160 INPUT Rho

170 PRINT "NUMBER OF ATOMS IN FORMULA?"

180 INPUT Iq

190 PRINT "ENTER 1 TO GENERATE A PLOTTING FILE OR ENTER O TO CALCULATE DEBYE T

$200 \quad$ INPUT YYYY

210 PRINT "IF YOU WISH TO PLOT INSERT A FORMATTED DISK AND PRESS CONTINUE"

220 PAUSE

230 IF YYYY=0 THEN 310

240 Tmin $=0$

$250 \quad T m=360$

260 Dt $=5$

$270 \quad$ Pmin $=0$

$280 \quad P m=360$

$290 \quad \mathrm{DP}=5$

300 GOTO 450

310 PRINT "FORMULA WEIGHT, IN GRAMS"

320 INPUT FormWt

330 PRINT "THETA MINIMUM ?"

340

350

360

370

380

390

400

410

420

430

440

450

460

470

480

490

500

510

INPUT Tmin

PRINT "THETA MAXIMUM ?"

INPUT Tm

PRINT "THETA INCREMENT ?"

INPUT DE

PRINT "PHI MINIMUM ?"

INPUT Pmin

PRINT "PHI MAXIMUM ?"

INPUT Pm

PRINT "PHI INCREMENT ?"

INPUT DP

Sy $=360 . / \mathrm{Pm} * 180 . / \mathrm{Tm}$

st $=0$

$S 1=0$

$\mathrm{Sm}=0$

$P=.01745329$

$D t t=D t$

$D t=D t * P$

$D p p=D p$

$D p=D p * P$

IF system $\$=$ "CUBIC" THEN 560

IF system $\$<>$ "CUBIC" THEN 690

PRINT "C $(1,1)$ ?"

INPUT $C(1,1)$

PRINT "C $(1,2)$ ?"

INPUT $C(1,2)$ 


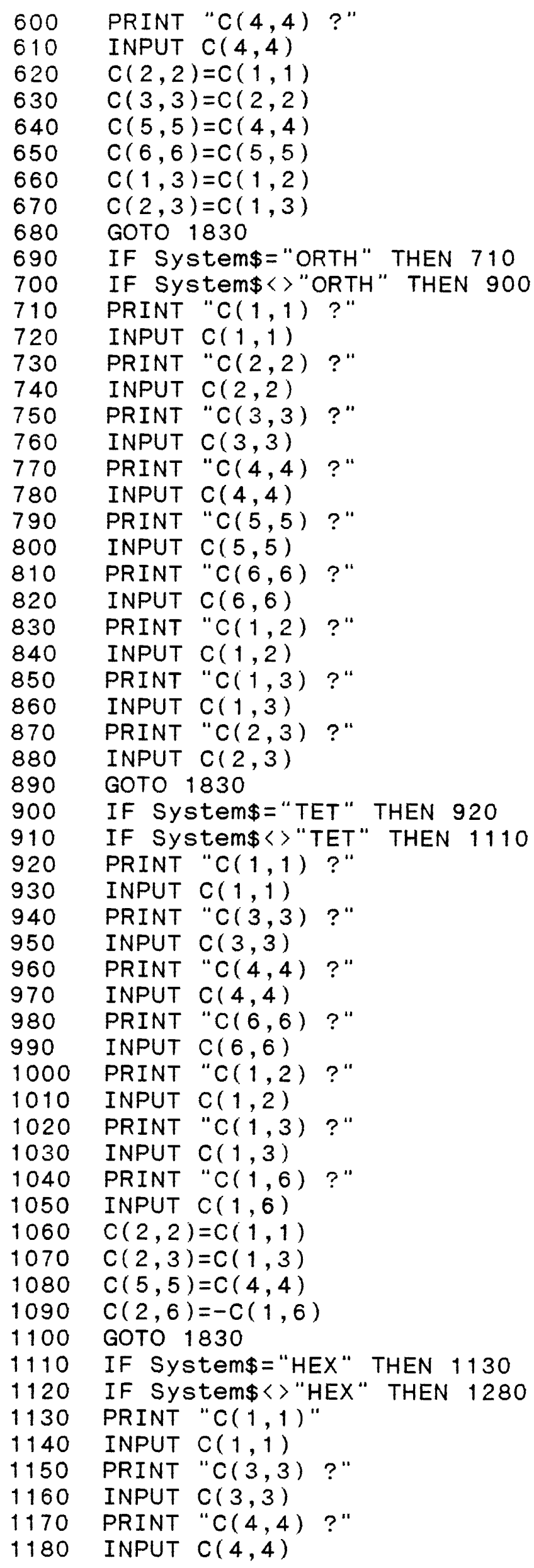




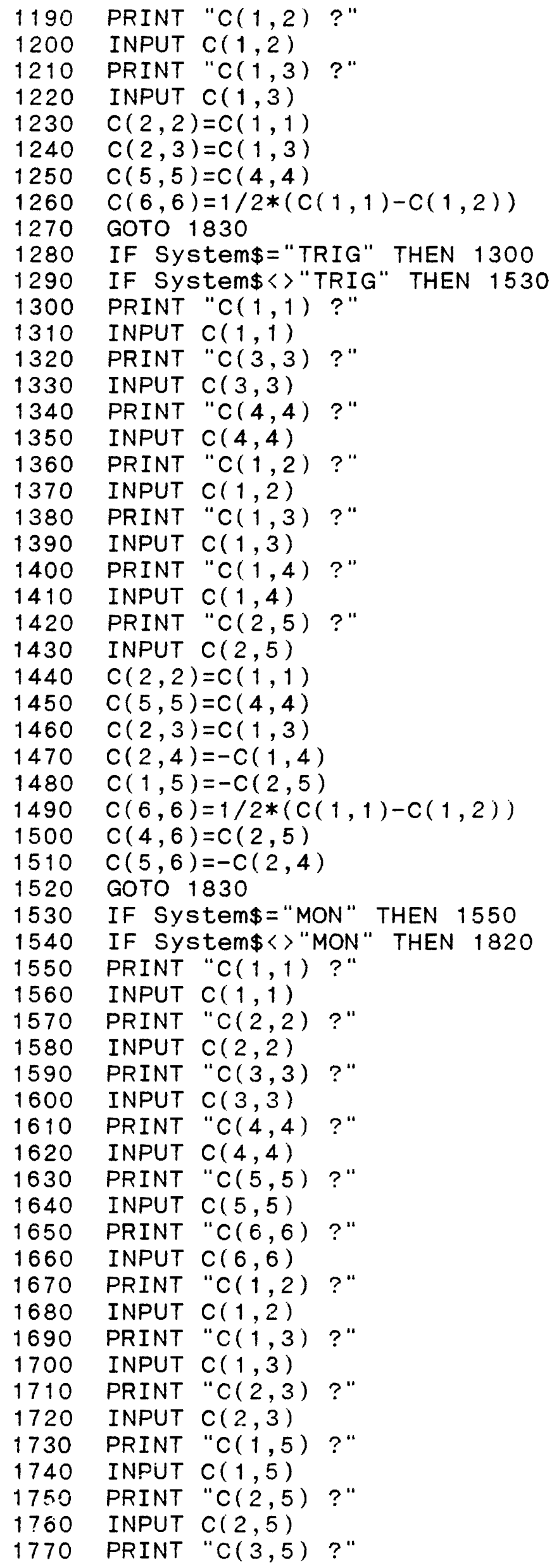




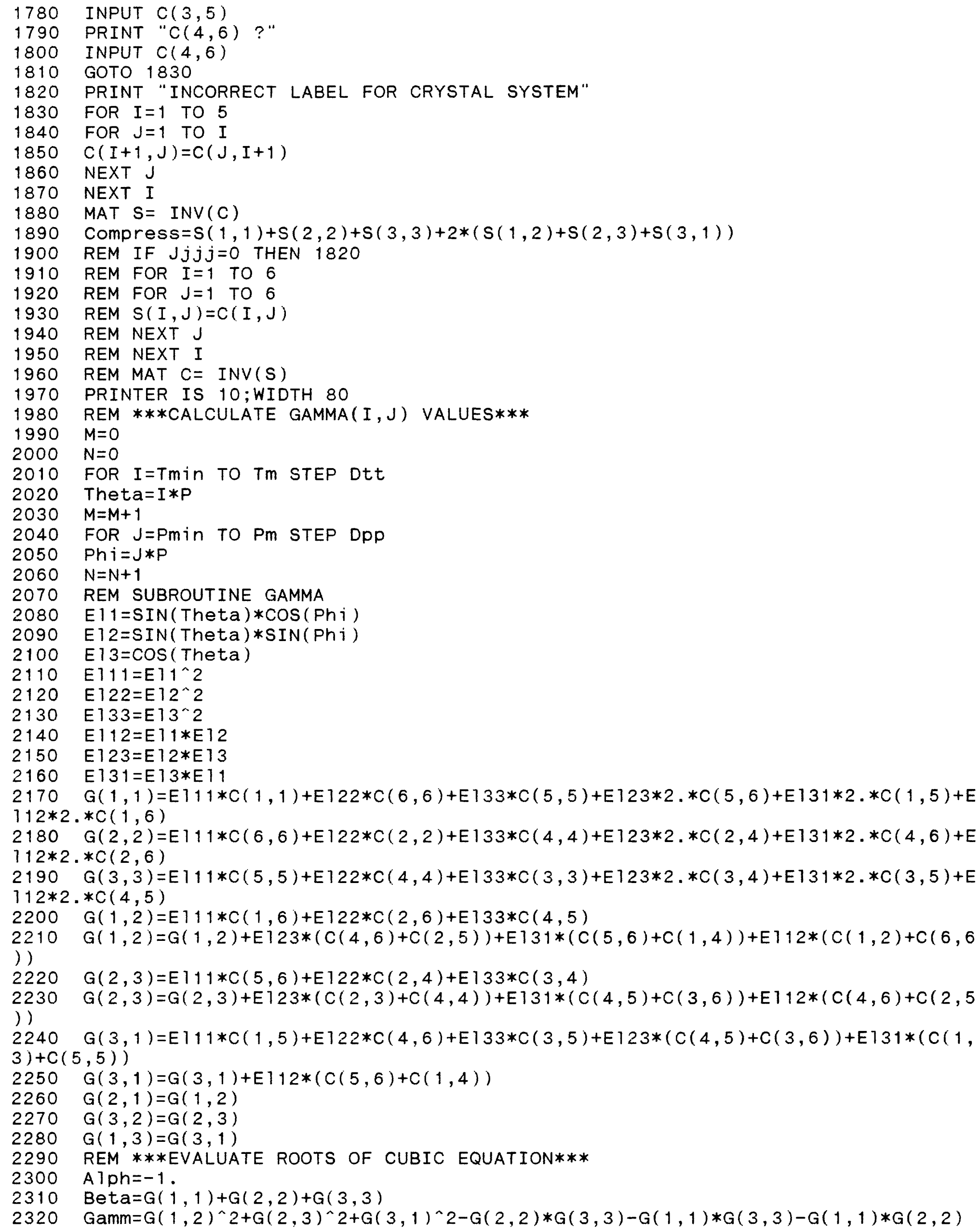


2330 Delta $=G(1,1) * G(2,2) * G(3,3)+2 . * G(1,2) * G(2,3) * G(3,1)-G(1,2)^{\wedge} 2 * G(3,3)-G(2,3)^{\wedge}$ $2 * G(1,1)$

2340 De1ta=De1ta- $\left(G(3,1)^{\wedge} 2\right) * G(2,2)$

$2350 H=\left(3 . * A 1 p h * G a m m-B e t a^{\wedge} 2\right) / 9 . / A 7 p h \wedge 2$

$2360 W=(\text { Beta/100. })^{\wedge} 3$

$2370 W=2 . * W / 27 . / A 7 \mathrm{ph}^{\wedge} 3$

$2380 W=W *(100.) \wedge 3$

$2390 \mathrm{G} 1=\mathrm{W}+(-\mathrm{A} 1 \mathrm{ph} * \mathrm{Beta} * \mathrm{Gamm} / 3 .+\mathrm{A} 1 \mathrm{ph} \wedge 2 * \mathrm{De} 1 \mathrm{ta}) / \mathrm{A} 1 \mathrm{ph}$ ^3

2400 Alp $=-G 1 / 2 . / S Q R(A B S(H))^{\wedge} 3$

$2410 \quad A a 1 p=A B S(A 1 p)$

2420 IF $(A a 1 p-1)<$.0 THEN GOTO 2480

2430 IF $(A a 1 p-1)>.=0$ THEN GOTO 2440

2440 A $1 f a=0$

2450 IF $(A 1 P)<0$ THEN GOTO 2470

2460 IF $(A T p)>=0$ THEN GOTO 2490

$2470 \quad$ Alf $\mathrm{a}=(180 . * 1.745329 \mathrm{E}-2)$

2480 A $7 \mathrm{fa}=(90 . * 1.745329 E-2)-\operatorname{ATN}\left(\mathrm{A} 7 \mathrm{p} /\left(1 .-\mathrm{A} 7 \mathrm{p}^{\wedge} 2\right)^{\wedge} .5\right)$

2490 Alfha $=A 1 \mathrm{fa} / 3$.

$2500 \quad A m=2 . * S Q R(-H)$

$2510 Z 1=A m * \operatorname{COS}(A 1 f h a)$

$2520 \quad Z 2=A m * \operatorname{Cos}(A 7 f h a+2.094395)$

$2530 \quad Z 3=A m * \operatorname{Cos}(A 1 \mathrm{fha}+4.188790)$

$2540 \times 1=Z 1-B e t a / 3 . / A 1 p h$

$2550 \times 2=Z 2-B e t a / 3 . / A 1 p h$

$2560 \times 3=$ Z3-Beta/3./A T ph

$2570 \times 1=(\operatorname{SQR}(X 1 / \mathrm{Rho})) * 1 . E+1$

$2580 \times 2=(S Q R(X 2 / R h o)) * 1 . E+1$

$2590 \times 3=(S Q R(X 3 / R h O)) * 1 . E+1$

2600 REM $* * *$ SORT VELOCITIES AS $V(3)>V(2)>V(1) * * *$

$2610 \quad V 1=X 1$

$2620 \quad \vee 2=\times 2$

$2630 \quad V 3=x 3$

2640 IF $V 1<=V 2$ THEN GOTO 2670

$2650 \quad V 1=X 2$

$2660 \quad V 2=X 1$

2670 IF $V 2<=V 3$ THEN GOTO 2710

$2680 \quad \times 1=V 2$

$2690 \quad V 2=V 3$

$2700 \quad \vee 3=X 1$

2710 IF $V 1<=V 2$ THEN GOTO 2750

$2720 \quad X 1=V 2$

$2730 \quad V 2=x 1$

$2740 \quad V 1=X 1$

2750

2760

2770

2780

2790

2800

2810

2820

2830

2840

2850

2860

2870

2880

2890

2900

$\operatorname{Rav}=1 / V 1^{\wedge} 3+1 / V 2^{\wedge} 3+1 / V 3^{\wedge} 3$

$A 1(M, N)=V 1$

$A 2(M, N)=V 2$

$A 3(M, N)=V 3$

$A 4(M, N)=\operatorname{RaV}$

REM ***NUMERICAL INTEGRATION FOR V(MEAN)***

$\mathrm{Th}=$ Theta

$D w=(\cos (T h)-\cos (T h+D t)) * D p$

IF $J=P m$ THEN 2880

IF $I=T m$ THEN 2880

$S t=S t+\left(1 . / V 1^{\wedge} 3+1 . / V 2^{\wedge} 3\right) * D W$

$S 1=S 1+D W / V 3^{\wedge} 3$

$S m=S m+R a v * D w$

NEXT J

$N=0$

NEXT I 
IF YYYY $=0$ THEN 3220

REM ** GENERATE PLOTTING FILES **

PRINT USING "19A, $X, D D . D D D D, X, 6 A "$; "MEAN SOUND VELOCITY--" ,Vm, "KM/SEC"

PRINT

PRINT USING "19A,X,DDDD.D,X,6A"; "DEBYE TEMPERATURE-- ", Debye, "KELVIN"

PRINT

PRINT USING "17A, X,DD.DD, X,6A" ; "COMPRESSIBILITY--" , Compress, "1/MBAR"

PRINT

PRINT "THE $C(I, J)$ IN MEGABARS" 
E"

3710

3)"

3720

3730

3740

3750

3760

3770

3780

3790

3800

3810

3820

3830

3840

3850

3860

3870

3880

3890

3900

$H E X Z$

3910

3920

E"

3930

3) "

PRINT

PRINT

PRINT

PRINT USING

PRINT USING

PRINT USING

"XX,DD.DDDD": $C(1,1), C(1,2), C(1,3), C(1,4), C(1,5), C(1,6)$

PRINT

PRINT

PRINT

PRINT

PRINT

PRINT

PRINT

PRINT

PRINT

PRINT

PRINT

PRINT

PRINT

PRINT

PLANE"

PRINT

PRINT

"SOUND

$11 X, 4(D D .4 D, X X), D D .4 D " ; C(2,2), C(2,3), C(2,4), C(2,5), C$
$" 20 X, 3(D D .4 D, X X), D D . D D D " ; C(3,3), C(3,4), C(3,5), C(3,6)$

"38X,DD.DDDD, $X X, D D$.DDDD"; $C(5,5), C(5,6)$

$" 47 X, D D . D D D D " ; C(6,6)$

\section{"THE S(I,J) IN RECIPROCAL MEgABARS"}

USING "XX,DD.DDDD"; $S(1,1), S(1,2), S(1,3), S(1,4), S(1,5), S(1,6)$

USING " $11 X, 4(D D .4 D, X X), D D .4 D " ; S(2,2), S(2,3), S(2,4), S(2,5), C(2,6)$

USING "20X, 3(DD.4D,XX),DD.DDDD";S(3,3),S(3,4),S(3,5),S(3,6)

USING "29X,DD.DDDD, XX,DD.DDDD, XX,DD.DDDD"; $S(4,4), S(4,5), S(4,6)$

USING "38X,DD.DDDD, XX,DD.DDDD"; $S(5,5), S(5,6)$

USING " $47 X, D D . D D D D " ; S(6,6)$

PRINT "THETA PHI

**TRANSVERSE**

V1

V2

LONGITUDINAL

RECIPROCIAL AVERAG

PRINT

PRINT

IF $\mathrm{Tm}<>180$ THEN 3780

IF Dtt $=5$ THEN $K=19$

IF $D t t=10$ THEN $K=10$

GOTO 3790

$K=T m / D t t+1$

$R=K$

$L=P m / D p p+1$

FOR $N=1$ TO $L$

$\mathrm{Ph}=(\mathrm{N}-1) * \mathrm{Dpp}$

IMAGE DDD.D, XXX,DDD.D, $X X X, D D . D D D, X X X, D D . D D D, X X X X X X, D D . D D D, 9 X, . D D D D D E$

PRINT USING $3830 ; 90, P h, A 1(R, N), A 2(R, N), A 3(R, N), A 4(R, N)$

NEXT N

PRINT

PRINT

PRINT

PRINT

PRINT

PLANE"

PRINT

PRINT "

\section{**TRANSVERSE**}

PHI

V1

V2

V3
RECIPROCIAL AVERAG

$$
\left(1 / V 1^{\wedge} 3+1 / V 2^{\wedge} 3+1 / V 3^{\wedge}\right.
$$

PRINT

PRINT

$I=1$

$\mathrm{K}=\mathrm{Tm} / \mathrm{Dt} t+1$

FOR $N=1$ TO $K$

Tht $=(N-1) * D t t$

PRINT USING 3830 ; Tht, Pmin, A1 (N, I ), A2 (N, I ), A3(N,I), A4(N,I)

NEXT N

PRINT

PRINT 
4040 PRINT "SOUND WAVE VELOCITY (IN KM/SEC) AS A FUNCTION OF THETA AND PHI IN T HE YZ PLANE"

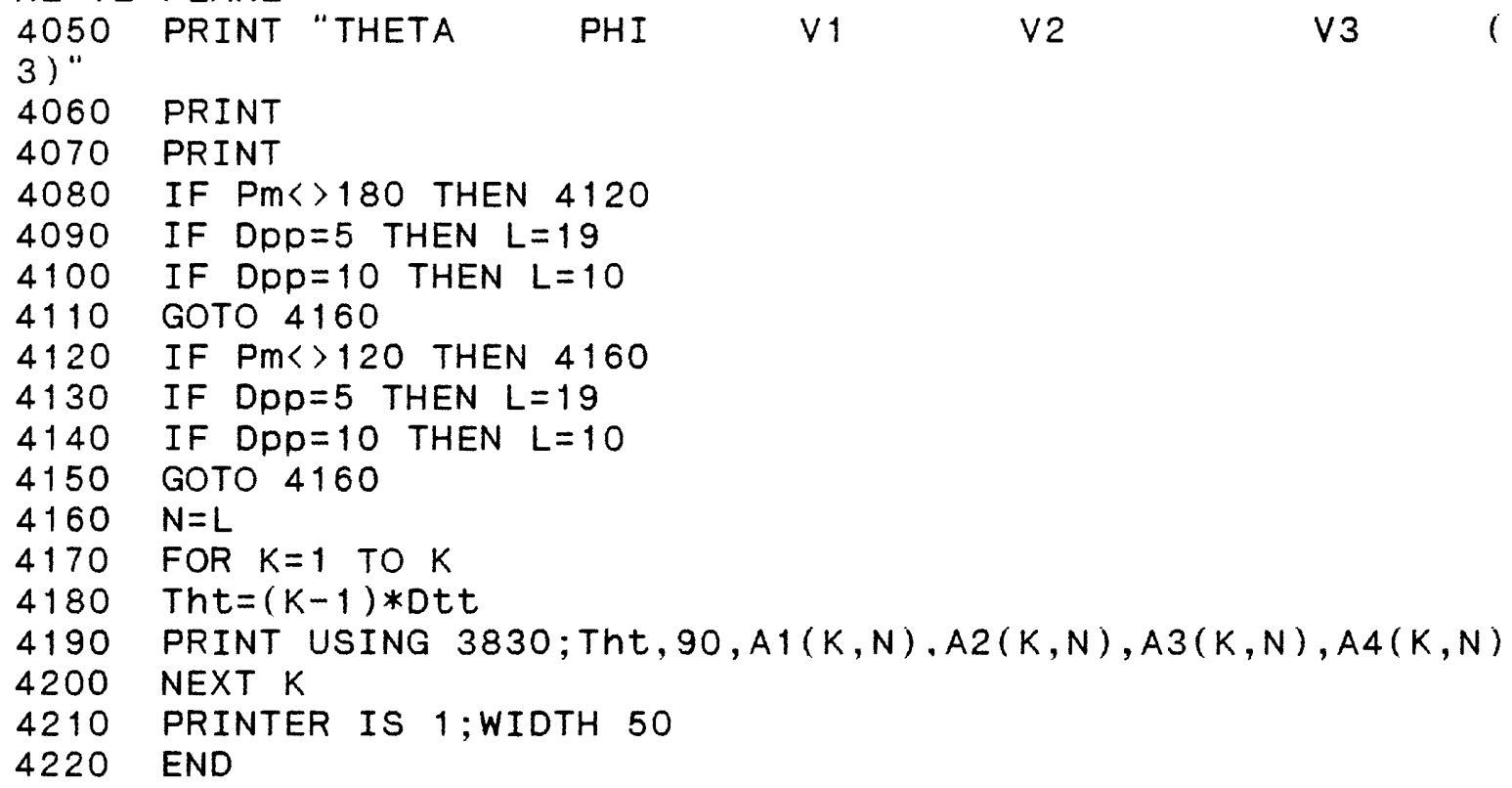

4220 END

V2

V3 